\title{
Expression efficiency of a scorpion neurotoxin, AaHIT, using baculovirus in insect cells
}

\author{
Kiyoko Taniai, 1,* Ahmet B. Inceoglu and Bruce D. Hammock ${ }^{2}$ \\ Department of Entomology, University of California Davis, Davis, CA 95616, U.S.A.
}

(Received 12 September 2001; Accepted 19 December 2001)

\begin{abstract}
Insect-selective neurotoxins are useful agents for developing recombinant baculoviral insecticides. AaHIT, one such toxin, was expressed in AcMNPV and had a dramatic effect on pest insects. However, the toxin production was relatively low. In order to identify reasons for the low production of recombinant AaHIT (rAaHIT) in insect cells, we analyzed the expression efficiency using Northern blotting, enzyme-linked immunosorbent assay, Western blotting, and a bioassay using Sarcophaga falculata larvae. The levels of rAaHIT mRNA and protein in Sf21 cells were comparable with those of another secreted protein, recombinant juvenile hormone esterase (rJHE), which was expressed in the same baculovirus system. However, the secretion efficacy of rAaHIT was significantly lower than that of rJHE. In addition, the toxic activity in the medium was approximately $1 \%$ of the total secreted rAaHIT. Western blot analyses suggested that rAaHIT aggregated and accumulated in cells. We attempted to increase the amount of soluble rAaHIT in cells using a co-expressed chaperonin, BiP. Although co-expressed BiP apparently increased the amount of soluble rAaHIT in cells, no improvement of active toxin production in the medium was detected. These results suggest that secretion and folding of rAaHIT are insufficient in insect cells.
\end{abstract}

Key words: Recombinant baculovirus, insect selective scorpion neurotoxin, AaHIT, BiP

\section{INTRODUCTION}

Several genetically engineered baculoviruses have been successfully developed to enhance the insecticidal activity of the original wild type virus. Almost all of these recombinant baculoviruses were constructed by the addition of foreign genes, such as insect hormone gene (Maeda, 1989), insect hormone esterase gene (Hammock et al., 1990) and insect specific toxin genes (Merryweather et al., 1990; Maeda et al., 1991; McCutchen et al., 1991; Stewart et al., 1991; Tomalski and Miller, 1991; Chejanovsky et al., 1995; Prikhod'ko et al., 1996; Hammock, 1999). Of those, insect selective neurotoxins from scorpions, spiders, mites and sea anemones are considered the most potent agents, since the recombinant viruses that incorporate these genes dramatically reduced lethal time 50 $\left(\mathrm{LT}_{50}, 16-50 \%\right)$ or lethal dose 50 of polyhedrin inclusion bodies $\left(\mathrm{LD}_{50}-\mathrm{PIB}, 11-39 \%\right)$ in commercially important pests. AaHIT is well characterized as one of the effective toxins isolated from Androctonus australis Hector (Darbon et al., 1982, 1991).
The toxin has 70 amino acid residues with four intramolecular disulfide bridges and binds to the insect sodium channel, causing rapid and sustained contractive paralysis. The synthetic AaHIT gene connected to a signal sequence from bombyxin (insect neurohormone) was inserted into Autographa californica nuclear polyhedrosis virus and the resulting virus was tested on Heliothis virescens larvae (McCutchen et al., 1991; Kunimi et al., 1996). The $\mathrm{LT}_{50}$ was $30 \%$ shorter, and $\mathrm{LD}_{50}$-PIB was $39 \%$ lower than those of wild type virus. In addition, the feeding damage on cotton plants was reduced much more than expected from the speed of kill since the paralyzed larvae fell off the plant many hours before their death (Hoover et al., 1995).

Although AcAaHIT had dramatically improved insecticidal capacity, there was one problem; its expression in both cell culture and insects was relatively low (McCutchen et al., 1991). The activity of the recombinant toxin in Sf21 cells and insect hemolymph was estimated at 2 and $1-2 \mu \mathrm{g} / \mathrm{ml}$, respectively. These concentrations represent much lower expression than that of other recombinant

\footnotetext{
* To whom correspondence should be addressed at: E-mail: taniai@affrc.go.jp

${ }^{1}$ Present address: Insect Biotechnology and Sericology Department, National Institute of Agrobiological Science, Tsukuba 305-8634, Japan

${ }^{2}$ Present address: Department of Entomology and Cancer Research Center, University of California Davis, Davis, CA 95616, U.S.A.
} 
viruses constructed in our laboratory. Although the genes were inserted under the $\mathrm{p} 10$ promoter of the same expression vector (pAcUW2B) as the AaHIT gene, the protein production was $96 \mu \mathrm{g} / \mathrm{ml}$ with the virus expressing juvenile hormone esterase (JHE, an exported soluble protein) (Bonning et al., 1992) and $200 \mu \mathrm{g} / \mathrm{ml}$ with the virus expressing mouse soluble epoxide hydrolase ( $\mathrm{msEH}$, an intracellular soluble protein) (Pinot et al., 1995).

We believe that improved toxin production may further increase the efficacy of AcAaHIT as a pesticide. In order to improve toxin production, it is necessary to elucidate the reason for the low expression. For this purpose, we analyzed mRNA level, toxin production, secretion and activity of AcAaHIT. Our results indicated that one of the reasons for the low expression was the intracellular accumulation and aggregation of rAaHIT. It has been shown that a co-expressed chaperone, BiP, increased secretion of bovine prochymosin in a yeast expression system (Harmsen et al., 1996) and improved functional antibody production in a baculovirus-cell culture system (Hsu et al., 1994). We tested the effect of overexpressed BiP with rAaHIT in insect cells. The co-expressed BiP apparently increased the solubility of rAaHIT in cells, however, no improvement in active toxin production was observed.

\section{MATERIALS AND METHODS}

Viruses and standard toxin. The following viruses were used. AcMNPV-C6: a wild type nuclear polyhedrosis virus of Autographa californica, AcAaHIT: a polyhedrin-positive (pol-positive) recombinant AcMNPV expressing synthetic AaHIT (McCutchen et al., 1991), AcJHE: a recombinant AcMNPV (pol-positive) expressing JHE from $\mathrm{He}$ liothis virescens (Ward et al., 1992), AcBB: a control recombinant AcMNPV (pol-negative) without foreign gene. AcBB-BiP: a recombinant AcMNPV (pol-negative) expressing murine immunoglobulin heavy chain binding protein (BiP) (Hsu et al., 1994). A natural AaHIT that was purified from the venom of scorpions by reversed phased HPLC using a $\mathrm{C}_{18}$ column (purity was more than 95\%) was a gift of Dr. Haim Moskowitz of our laboratory.

Cell culture and insects. Sf 21 cells were maintained using Ex-Cell 401 medium (JRH Bio- sciences) supplemented with 3\% fetal calf serum (GibcoBRL) and 1\% Penicillin-Streptomycin. Tobacco budworm eggs were obtained from the United States Department of Agriculture/Agricultural Research Station (Stoneville, MS). The larvae were reared on a semi-synthetic diet (Hunter et al., $1984)$ at $26^{\circ} \mathrm{C}, 16 \mathrm{~L}: 8 \mathrm{D}$ and were used at day 1 of the fifth-stadium.

Infection and sample preparation. Sf 21 cells $\left(1.0 \times 10^{6}\right.$ cells per $35 \mathrm{~mm}$ dish) were infected with budded virus (virus-infected Sf21 cell culture medium) at a multiplicity of infection (MOI) of 10 plaque-forming units (PFU) per cell. At multiple times post infection, cells were removed from dishes with a Cell Scraper (Fisher Scientific). Cells and medium were separated by centrifugation at $700 \times g$ for $10 \mathrm{~min}$ at $4^{\circ} \mathrm{C}$. The cell pellet was washed twice with $0.1 \mathrm{M}$ sodium phosphate buffer (pH 7.5) containing $1 \mathrm{~mm}$ EDTA (PBE). The medium and cells were kept at $-20^{\circ} \mathrm{C}$ until use. Just before use, cells were homogenized in PBE containing $0.5 \mu \mathrm{g} / \mathrm{ml}$ Pepstatin A, $1 \mu \mathrm{g} / \mathrm{ml}$ Leupeptin and $150 \mu \mathrm{g} / \mathrm{ml}$ PMSF. Then soluble proteins were separated from cell debris, nuclei and insoluble proteins by centrifugation at $10,000 \times g$ for 20 min. The supernatant was designated as the soluble fraction. The pellet was suspended with PBE, and dissolved with sample buffer for SDS-PAGE. Insects were infected with $5 \times 10^{5}$ PFU of virus by injection using a Hamilton syringe, placed on a diet at $26^{\circ} \mathrm{C}$ and held on an 18:6 light: dark cycle. The haemolymph was collected at 48 and $72 \mathrm{~h}$ p.i. in a tube containing phenyl thiourea, and kept at $-20^{\circ} \mathrm{C}$.

Enzyme-linked immunosorbent assay (ELISA). Serial 10-fold dilutions of the samples were made in triplicate with $48 \mathrm{mM}$ sodium carbonate buffer (pH 9.6). ELISA plates (Nunc, F96 MAXISOPE) were coated with $100 \mu \mathrm{l} /$ well of each sample at $4^{\circ} \mathrm{C}$ overnight. As the standard coating proteins, $0.01,0.1,1,10,100 \mu \mathrm{g}$ of purified natural AaHIT or JHE was placed in each well, and lysed cells infected with wild-type virus (AcMNPV) were also used as a control. The remaining surface of the wells was blocked with $200 \mu \mathrm{l} /$ well of phosphate buffered saline (PBS) plus 10\% nonfat milk (Bio$\mathrm{Rad}$ ) at room temperature (RT) for $2 \mathrm{~h}$. First (antiAaHIT or anti-JHE rabbit polyclonal) and second (peroxidase-conjugated goat anti-rabbit IgG, BioRad) antibodies were diluted with PBS and used at 
$100 \mu 1$ per well, and incubated at $37^{\circ} \mathrm{C}$ for $2 \mathrm{~h}$ for each reaction. Substrate was prepared as follows: $0.4 \mathrm{ml}$ of $0.6 \% 3,3^{\prime} 5,5$-tetramethylbenzidine dissolved in dimethylsulfoxide, and $0.1 \mathrm{ml}$ of $0.1 \%$ $\mathrm{H}_{2} \mathrm{O}_{2}$ was mixed with $25 \mathrm{ml}$ of $100 \mathrm{~mm}$ citrate-acetate buffer ( $\mathrm{pH}$ 5.5). The substrate was added at $100 \mu \mathrm{l} /$ well and incubated at RT for $15 \mathrm{~min}$. The reaction was quenched with $50 \mu \mathrm{l}$ of $4 \mathrm{~N}_{2} \mathrm{SO}_{4}$ and plates were read using a plate reader (Molecular Devices) at $450 \mathrm{~nm}$.

Western blotting. Proteins of the Sf 21 cells or insect hemolymph were analyzed by SDS-PAGE on $15 \%$ polyacrylamide gels, transferred onto a nitrocellulose membrane (Trans-Blot Transfer Medium, Bio-Rad) and probed with anti-AaHIT polyclonal antibodies, and goat anti-rabbit IgG conjugated with horse radish peroxidase (HRP) as the secondary antibody. The pre-stained molecular size markers $(4,6,17,22,30,42$ and $60 \mathrm{kDa}$ ) (Novel Experimental Technology) were used to determine molecular size of rAaHIT. HRP was detected using an ECL and Western blotting detection reagents (Amersham) and chemiluminescence signals were exposed to X-ray film. The cells infected with AcMNPV were used as controls. X-ray films were scanned by a ScanJet 4C (Hewlett Packard), and the bands were analyzed using Basic Quantifier software (Genomic Solutions).

Northern blot analysis. Total RNA was extracted from Sf21 cells using ISOGEN (Nippon Gene). RNA pellet was dissolved in $50 \mathrm{~mm}$ Tris$\mathrm{HCl}, \mathrm{pH} \mathrm{7.5}$, containing $10 \mathrm{~mm} \mathrm{MnCl}_{2}$, and 3 units of DNase I was added to each $10 \mu \mathrm{g}$ of the RNA to ensure complete removal of viral DNA. After RNA was incubated with DNase I for $15 \mathrm{~min}$ at $37^{\circ} \mathrm{C}$, $5 \mu \mathrm{g}$ of each mRNA sample was electrophoresed on a $1.2 \%$ agarose gel containing $6.6 \%$ formaldehyde. The gel was washed in water for $40 \mathrm{~min}$, and then stained with ethidium bromide solution to visualize the bands of $28 \mathrm{~S}$ ribosomal RNA for internal markers. The total RNA was transferred onto a Hybond-N+ membrane (Amersham) and hybridized with cDNA probe labeled with $\left[\alpha{ }_{-}^{32} \mathrm{P}\right] \mathrm{dCTP}$ using Prime-a Gene Labeling system (Promega). The hybridization was performed overnight at $42^{\circ} \mathrm{C}$ in $50 \%$ formamide, $5 \times$ SSC, $5 \times$ Denhart's, $1 \%$ SDS, $0.2 \%$ sodium-phosphate $(\mathrm{pH} 7.0), 0.1 \mathrm{mg} / \mathrm{ml}$ of salmon sperm DNA and $9.5 \times 10^{6} \mathrm{cpm}$ of each probe. The probes were prepared using the plasmids, pTZ18R.AaIT (Mc-
Cutchen et al., 1991) and 3hv16B (Hammock et al., 1990). The membrane was washed twice in $2 \times$ $\mathrm{SSC}$ at room temperature, and twice in $0.2 \times \mathrm{SSC}$, $0.1 \%$ SDS at $60^{\circ} \mathrm{C}$ for $30 \mathrm{~min}$. The RNA signal was detected by exposure of the membrane to Xray film overnight at $-80^{\circ} \mathrm{C}$. Relative intensity of the bands was determined in the same way as the Western blot bands.

Co-infection of two viruses. $\mathrm{Sf} 21$ cells were coinfected with AcAaHIT and AcBB-BiP at MOI of 3 PFU for each virus. As controls, co-infection of AaHIT and AcBB, and single infection of AcAaHIT were used at MOI of 3 PFU. After 3 days infection, the soluble proteins were prepared by the same method described in the Western blotting section. After the soluble proteins were removed from $10,000 \times g$ run pellets, the pellets were directly suspended in SDS-PAGE sample buffer and boiled for $5 \mathrm{~min}$, then used as insoluble proteins for SDS-PAGE analysis.

\section{RESULTS}

\section{Expression of AaHIT and JHE}

The expression levels of AaHIT and JHE genes in the baculoviruses were compared by Northern blot analysis. The intensity of each mRNA band was divided by the intensity of the $28 \mathrm{~S}$ ribosomal RNA band, and the relative intensities of the samples were shown in the graph (Fig. 1). AaHIT gene was stably expressed during 48 to 96 h p.i., whereas expression of JHE was highest at 48-72 h p.i. then declined at $96 \mathrm{~h}$ p.i. Overall expressions of the two genes were comparable during the 4 days, indicating that AaHIT-mRNA appear to be as stable as JHE-mRNA.

\section{Production of rAaHIT and rJHE in Sf21 cells}

Soluble recombinant proteins in the medium and cells were measured by ELISA (Table 1). All values were corrected by subtraction of the non-specific reaction with AcMNPV. When proteins were prepared from cells, the insoluble fraction was eliminated by centrifugation. Therefore, the total recombinant protein in cells was not evaluated in this assay. There was a significant difference in the expression of rAaHIT and rJHE. The measured rAaHIT in the medium was 5.7-fold lower, but in cells it was 40 to 100 fold higher in quantity than the level of rJHE at the peak time of expression (48 

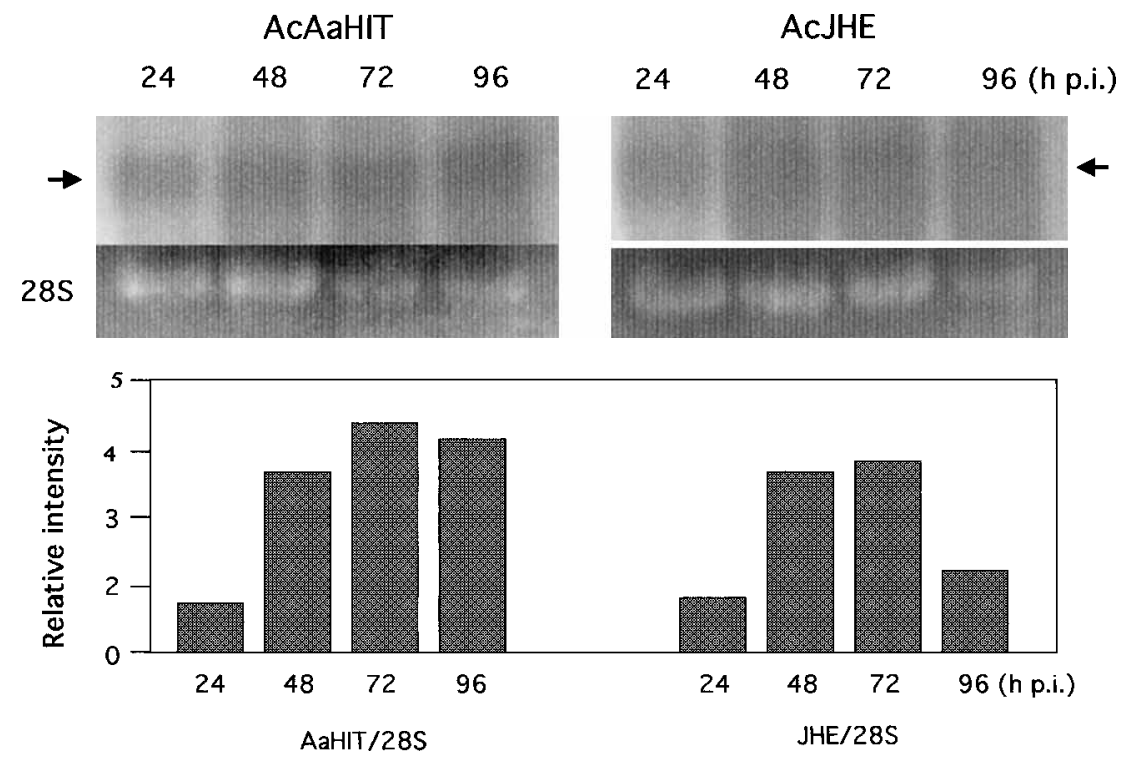

Fig. 1. Expression of the AaHIT and JHE genes in the recombinant baculoviruses. Total RNAs from Sf21 cells infected with AcAaHIT or AcJHE at 24, 48, 72, and $96 \mathrm{~h}$ p.i. were electrophoresed in a $1.2 \%$ agarose gel containing $6.6 \%$ formaldehyde, and then transferred onto a nylon membrane, which was hybridized with ${ }^{32} \mathrm{P}$-labeled AaHIT or JHE probes. The upper panel shows mRNA signals. The leftward-pointing arrowhead indicates AaHIT bands and the rightward ones indicates JHE bands. The middle panel shows 28S ribosomal RNA stained with ethidium bromide as the internal marker. The lower panel depicts the relative intensities of mRNA signals.

Table 1. Production of rAaHIT and rJHE in the baculoviruses

\begin{tabular}{clrrrr}
\hline & & \multicolumn{4}{c}{ Mean \pm SE $(\mu \mathrm{g} / \mathrm{ml})$} \\
\cline { 3 - 5 } & & 24 (h p.i.) & 48 & 72 \\
\hline \multirow{2}{*}{ rAaHIT } & medium & $0.9 \pm 0.1$ & $7.9 \pm 0.0$ & $10.1 \pm 0.5$ & $12.7 \pm 3.1$ \\
& cells & $0.2 \pm 0.2$ & $13.1 \pm 0.3$ & $12.9 \pm 0.3$ & $10.7 \pm 0.1$ \\
rJHE & medium & $13.6 \pm 0.4$ & $35.8 \pm 0.1$ & $57.7 \pm 3.8$ & $71.9 \pm 2.3$ \\
& cells & $0.1 \pm 0.0$ & $0.5 \pm 0.0$ & $0.3 \pm 0.1$ & $0.1 \pm 0.0$ \\
\hline
\end{tabular}

The concentrations of rAaHIT and rJHE in Sf21 cells were measured by ELISA using anti-AaHIT or anti-JHE antibodies as primary antibodies. Standard curves were made using a natural AaHIT from scorpion venom purified using HPLC, and a rJHE from AcJHE-infected cell culture medium purified using affinity column chromatography. All values were corrected by controls, which were non-specific proteins from Sf21 cells infected with AcMNPV, and then given per $1 \mathrm{ml}$ cell culture. The SE was calculated from triplicate assays.

and $72 \mathrm{~h}$ p.i.) based on weight. At each time point, more than $95 \%$ of the rJHE was secreted in the medium, however, less than $45 \%$ of the rAaHIT was secreted at the same time p.i. Even with the low level of secretion, $7.9 \mu \mathrm{g} / \mathrm{ml}$ ( $48 \mathrm{~h}$ p.i.) and $10.1 \mu \mathrm{g} / \mathrm{ml}$ (72 h p.i.) of rAaHIT was detected in medium, and $13.1 \mu \mathrm{g} / \mathrm{ml}(48 \mathrm{~h}$ p.i.) and $12.9 \mu \mathrm{g} / \mathrm{ml}$ (72 h p.i.) was detected in cell lysate. These values were compared with active toxin concentrations determined by subsequent bioassay experiment.

\section{Western blot analysis of Sf21 cells and hemo- lymph}

rAaHIT in total cell-homogenate was analyzed in SDS-PAGE under reducing or non-reducing conditions followed by Western blotting (Fig. 2). A major band of $6 \mathrm{kDa}$ was observed with the second major bands at around 12 to $18 \mathrm{kDa}$, and with a few minor bands of larger than $30 \mathrm{kDa}$ under reducing conditions. The migration position of the $6 \mathrm{kDa}$ band was indistinguishable from the natural AaHIT protein (data not shown). The band of 12 to 


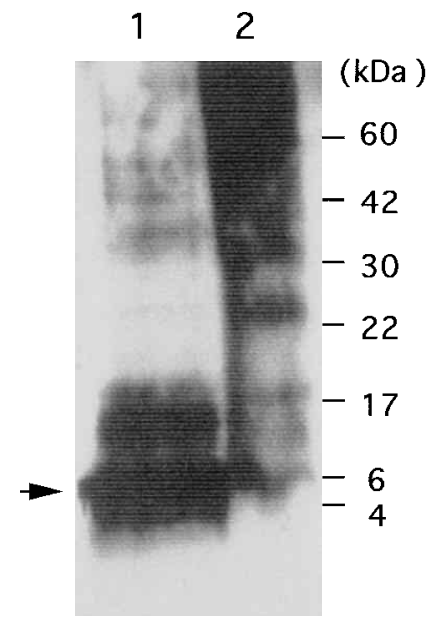

Fig. 2. Western blot analysis of rAaHIT in Sf21 cells. Cells were infected with AcAaHIT, and then harvested at $72 \mathrm{~h}$ p.i. Cell pellets were dissolved in sample buffer with (lane 1) or without (lane 2) $\beta$-mercaptoethanol and boiled for $5 \mathrm{~min}$. The proteins were separated in a $15 \%$ SDS-PAGE gel, and then transferred onto a nitrocellulose membrane. The rAaHIT bands were visualized with anti-AaHIT polyclonal antibodies, and reacted with goat anti-rabbit conjugated with HRP (horse radish peroxidase) using the ECL detection system. The position of molecular size markers is indicated to the left.

$18 \mathrm{kDa}$ seems to be dimer, and a trimer of rAaHIT which probably appeared because of insufficient reducing reagent in the sample. The other faint bands with higher molecular size were unknown proteins. In contrast, multiple bands of different sizes appeared under the non-reducing condition. These bands were $6,18,24,30 \mathrm{kDa}$ and more than $40 \mathrm{kDa}$. The sizes of the lower three bands correspond to a trimer, tetramer and pentamer of $6 \mathrm{kDa}$. Some of these oligomers could be products of the effect of mercaptoethanol diffused from the sample in the next lane. No signal was observed with cells infected with AcMNPV (data not shown).

\section{Quantitative Western blotting}

rAaHIT of the virus-infected insect hemolymph was quantified by SDS-PAGE followed by Western blotting (Fig. 3). One and $0.5 \mu \mathrm{l}$ of hemolymph from fifth-stadium larvae of $H$. virescens at $72 \mathrm{~h}$ p.i. were compared with 50 and $250 \mathrm{ng}$ of natural AaHIT on an SDS-PAGE gel. The signal intensity of $1 \mu 1$ of hemolymph was comparable to $250 \mathrm{ng}$ of standard protein. The intensity of $0.5 \mu \mathrm{l}$ of hemolymph was about half of this standard AaHIT band. From these results, the concentration of rAaHIT was estimated to be approximately 250
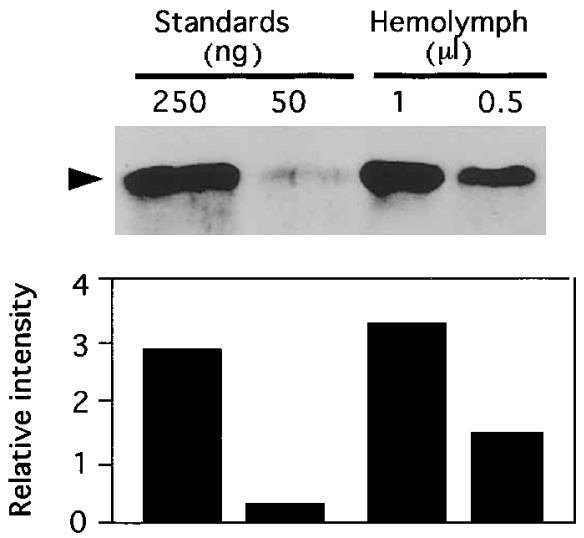

Fig. 3. Quantitative Western blotting of rAaHIT in insect hemolymph. Hemolymph from larvae infected with AcAaHIT was harvested $72 \mathrm{~h}$ p.i. One microliter of the hemolymph was diluted with $4 \mu \mathrm{l}$ of water and mixed with $15 \mu \mathrm{l}$ of sampletreatment buffer under reducing conditions. The sample was boiled for $5 \mathrm{~min}$ and the proteins were separated in a $15 \%$ SDS-PAGE gel. Western blotting and detection were as in Fig. 2. The upper panel shows Western blots. The arrowhead indicates rAaHIT. The lower panel shows the relative intensity of the bands.

Table 2. Minimum volume causing immediate paralysis of blow fly larvae

\begin{tabular}{lcr}
\hline & $48 \mathrm{~h}$ p.i. & $72 \mathrm{~h}$ p.i. \\
\hline Medium & $10.0 \pm 0.01 \mu \mathrm{l}$ & $16.1 \pm 3.0 \mu \mathrm{l}$ \\
& $(100 \mathrm{ng} / \mathrm{ml})^{\mathrm{a}}$ & $(62 \mathrm{ng} / \mathrm{ml})^{\mathrm{a}}$ \\
Cell lysate & not detected & not detected \\
Hemolymph & $2.0 \pm 0.7 \mu \mathrm{l}$ & $1.2 \pm 0.2 \mu \mathrm{l}$ \\
& $(500 \mathrm{ng} / \mathrm{ml})^{\mathrm{a}}$ & $(833 \mathrm{ng} / \mathrm{ml})^{\mathrm{a}}$ \\
\hline
\end{tabular}

${ }^{a}$ The active rAaHIT concentrations in parenthesis were calculated using a minimum amount of a standard natural AaHIT (1 ng) causing immediate paralysis.

$\mu \mathrm{g} / \mathrm{ml}$ in infected insect hemolymph.

\section{Bioassay of rAaHIT}

Active toxin concentrations in medium, cell lysate (soluble fraction) and insect hemolymph were determined by injection of serial dilutions of the samples to blow fly larvae (Table 2). A natural purified AaHIT was injected as a control, and the minimum amount that caused immediate paralysis of the larvae was determined to be $1 \mathrm{ng}$. The volumes causing immediate paralysis in the medium and hemolymph were $10 \mu \mathrm{l}(48 \mathrm{~h}$ p.i.) to $16.1 \mu \mathrm{l}$ (72h p.i.), and $1.2 \mu \mathrm{l}$ (72h p.i.) to $2 \mu \mathrm{l}$ (48h p.i.), respectively (Table 2). No biological activity was found in cell lysate at any time post infection, al- 


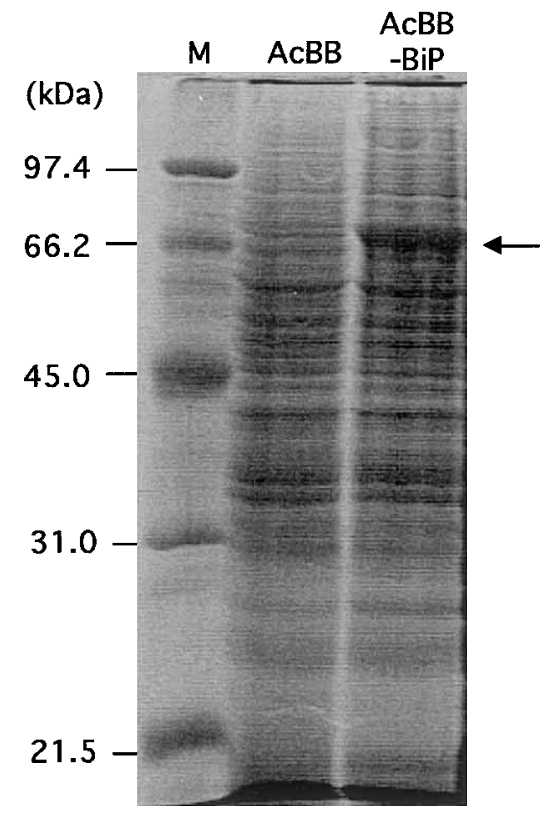

Fig. 4. Expression of BiP in AcBB-BiP. Sf21 cells infected with AcBB-BiP were harvested 72 h p.i. Proteins from the whole cell homogenate were separated on a $15 \%$ SDSPAGE gel. The arrow indicates recombinant BiP (ca. $70 \mathrm{kDa}$ ). Molecular size markers are shown on the left.

though ELISA experiments showed 10.7-13.1 $\mu \mathrm{g} / \mathrm{ml}$ of rAaHIT in cell lysate (Table 1). Active rAaHIT in the medium was only $1 \%(62-100$ $\mathrm{ng} / \mathrm{ml}$ ) of the amounts detected by ELISA (7.9$10.1 \mu \mathrm{g} / \mathrm{ml}$ ), and in the hemolymph it was $0.3 \%$ $(0.8 \mu \mathrm{g} / \mathrm{ml})$ of the amount detected by quantitative Western blotting $(250 \mu \mathrm{g} / \mathrm{ml})$.

\section{Co-infection of AcAaHIT with AcBB-BiP}

Soluble and insoluble fractions of co-infected cells with two different viruses and controls at $72 \mathrm{~h}$ p.i. were analyzed by reducing SDS-PAGE followed by Western blotting. The expression of BiP in AcBB-BiP was confirmed in an SDS-PAGE gel using the soluble fraction of the infected cells (Fig. 4). SDS-PAGE of the soluble fraction (Fig. 5A) indicates that co-expressing $\mathrm{BiP}$ apparently increased soluble AaHIT in comparison with the two controls, AcAaHIT single infection, and co-infection of AcAaHIT and AcBB. However, similar to the controls, insoluble AaHIT still remained (Fig. 5B). The toxicity of the mediums was tested using blow flies. Co-expressed BiP did not increase active toxin concentration at all (data not shown). The concentration of inactive rAaHIT was not measured.

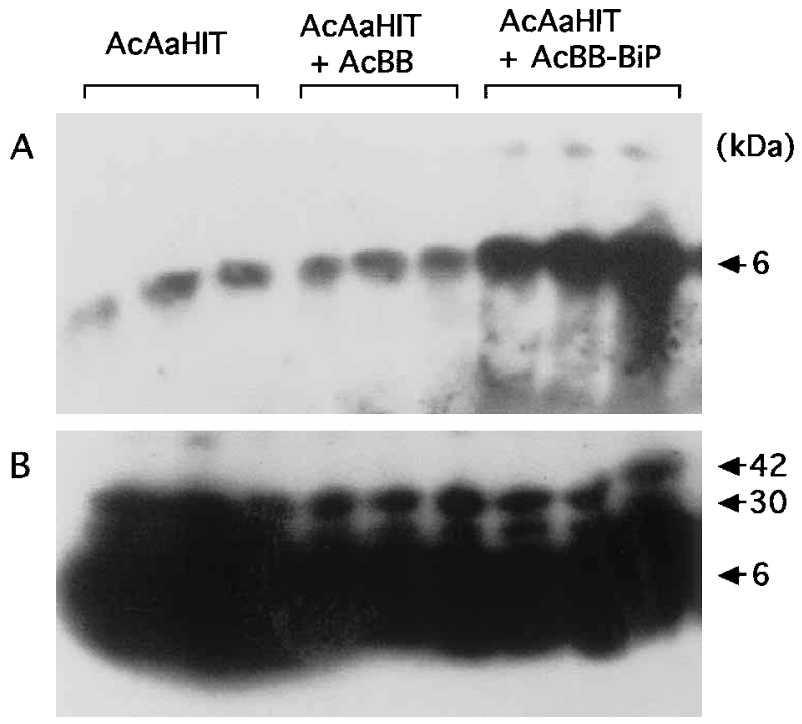

Fig. 5. Increased soluble rAaHIT with co-expressed BiP. Sf21 cells were infected with the following viruses: AcAaHIT (control), AcAaHIT co-infected with AcBB (negative control), and AcAaHIT co-infected with AcBB-BiP. Cells were harvested $72 \mathrm{~h}$ p.i. and proteins were analyzed by SDS-PAGE under reducing conditions. A: soluble rAaHIT. B: insoluble rAaHIT. Arrows indicate the molecular sizes of the bands.

\section{DISCUSSION}

We examined the expression efficiency of rAaHIT in AcAaHIT to elucidate the reasons for low toxin production. Although the levels of expressed mRNA and protein were comparable to those of rJHE, at least two problems were identified: 1) there was low secretion, and 2) there was a low percentage of active toxin $(0.3-1.0 \%)$ in both medium and hemolymph. The secretion pathway has many steps: post-translational modification, signal peptide cleavage, transport to the endoplasmic reticulum (ER), folding in the ER, transport through the Golgi apparatus, and glycosylation. The cDNA sequence of AaHIT indicates that, except for cleavage of the signal peptide, post-translational processing, such as peptidase digestion, amidation, and glycosylation, are not required (Bougis et al., 1989). Since we used a signal sequence derived from bombyxin of Bombyx mori, signal peptide cleavage could be insufficient. The use of an alternate signal sequence derived from the Drosophila cuticle gene for expression of a mite toxin gene, tox34, suggested inadequate cleavage ( $\mathrm{Lu}$ et al., 1996). For rAaHIT, signal peptide cleavage seems to be adequate based on the equiva- 
lent molecular size of rAaHIT and natural AaHIT in SDS-PAGE gels (Fig. 3), and the equivalent isoionic points of rAaHIT and natural AaHIT (unpublished result of Dr. H. Moskowitz). Therefore, the low secretion probably results from other secretion steps. Lu et al. (1996) tested the effects of several different promoters on expression of the tox 34 gene in baculovirus. The level of toxin secretion was very poor when it was expressed under the control of two strong promoters derived from the AcMNPV genome. By contrast, when the toxin was expressed under the Hsp70 promoter from Drosophila, which was the weakest promoter they tested, the secretion level was high, but overall production was quite small. These results suggest that production of the toxin in insect cells is limited. A similar phenomenon might occur in expression of rAaHIT. If rAaHIT is expressed under a very weak promoter and only a limited amount is produced, the level of secretion might increase.

Western blot analyses (Fig. 5B) indicated that insoluble rAaHIT accumulated in cells. This might be involved in the low level of secretion. The insoluble rAaHIT might be a misfolded protein. If some of the misfolded rAaHIT is secreted, the toxic activity of the secreted rAaHIT is likely to be decreased. Misfolding of rAaHIT in insect cells might be tied to both problems: low secretion and low activity.

Hsu et al. (1994) reported that co-expressed BiP increased intracellular soluble immunoglobulin expressed in a baculovirus-insect cell culture system. $\mathrm{BiP}$ is an ER-residing chaperone that assists the folding of newly translocated proteins and removes misfolded proteins (Gething and Sambrook, 1992; Hendrick and Hartl, 1993). Since BiP homologues are widely distributed in eukaryotic cells, including insects (Rubin et al., 1993), this protein probably has a common role in the processing of newly synthesized secreted proteins in mammals and insects. Therefore, we tested the effect of overexpressedmurine BiP on improving soluble rAaHIT production. Co-expressed BiP apparently increased soluble rAaHIT in cells (Fig. 5A), suggesting that expressed $\mathrm{BiP}$ is associated with rAaHIT. However, BiP did not improve the active rAaHIT concentration in cell culture medium (data not shown). We assume that some other factor(s) are required to increase functional rAaHIT secretion and production.

We observed that the isolated natural AaHIT formed a ladder pattern in SDS-PAGE gels (data not shown). Similarly, another scorpion neurotoxin, Lqh $\alpha$ IT, produced a ladder pattern in SDS-PAGE gels (Chejanovsky et al., 1995). This result tempts us to speculate that isolated scorpion toxins have a feature that causes aggregation. To prevent the aggregation of these toxins in the venom gland, scorpions might produce aggregation-inhibiting proteins or may have some system to maintain redox conditions in venom gland cells. It will be useful to look for the factors that prevent aggregation and promote correct folding of rAaHIT in scorpion venom glands.

\section{ACKNOWLEDGEMENTS}

We thank Dr. Michael J. Betenbaugh of Johns Hopkins University for providing the AcBB and AcBB-BiP. This work was supported by the USDA competitive Research Grants Program (94-37302-0567), US/Israel BARD/USDA (\#IS-2530-95C), UC Systemwide Biotechnology Research and Education Program, UCD is an EPA Center for Ecological Health Research (CR819658) and a MEHS of Environmental Health (P30 E505787). A. B. Inceoglu is supported by Ankara University.

\section{REFERENCES}

Bonning, B. C., M. Hirst, R. D. Possee and B. D. Hammock (1992) Further development of a recombinant baculovirus insecticide expressing the enzyme juvenile hormone esterase from Heliothis verescens. Insect Biochem. Molec. Biol. 22: 453-458.

Bougis, P. E., H. Rochat and L. A. Smith (1989) Precursors of Androctonus australis scorpion neurotoxins. J. Biol. Chem. 264: 19259-19265.

Chejanovsky, N., N. Zilberberg, H. Rivkin, E. Zlotkin and M. Gurevitz (1995) Functional expression of an alpha antiinsect scorpion neurotoxin in insect cells and lepidopterous larvae. FEBS Lett. 376: 181-184.

Darbon, H., C. Weber and W. Braun (1991) Two-dimensional $1 \mathrm{H}$ nuclear magnetic resonance study of AaHIT, an antiinsect toxin from the scorpion Androctonus australis Hector. Sequential resonance assignments and folding of the polypeptide chain. Biochemistry 30: 1836-1845.

Darbon, H., E. Zlotkin, C. Kopeyan, J. V. Rietschoten and H. Rochat (1982) Covalent structure of the insect toxin of the North African scorpion Androctonus australis Hector. Int. J. Peptide Protein Res. 20: 320-330.

Gething, M.-J. and J. Sambrook (1992) Protein folding in the cell. Nature 355: 33-45.

Hammock, B. D. (1999) The quest for a recombinant viral pesticide. A tribute to Susumu Maeda. RIKEN Rev. 22: 9-13.

Hammock, B. D., B. C. Bonning, R. D. Possee, T. N. Hanzlik and S. Maeda (1990) Expression and effects of the juvenile hormone esterase in a baculovirus vector. Nature 344: 458-461.

Harmsen, M. M., M. I. Bruyne, H. A. Raué and J. Maat (1996) 
Overexpression of binding protein and disruption of the PMR1 gene synergistically stimulate secretion of bovine prochymosin but not plant thaumatin in yeast. Appl. Microbiol. Biotechnol. 46: 365-370.

Hendrick, J. P. and F.-U. Hartl (1993) Molecular chaperone functions of heat-shock proteins. Annu. Rev. Biochem. 62: 349-384.

Hoover, K., C. M. Schultz, S. S. Lane, B. C. Bonning, S. S. Duffey, B. F. McCutchen and B. D. Hammock (1995) Reduction in damage to cotton plant by a recombinant baculovirus that knocks moribund larvae of Heliothis virescens off the plant. Biol. Control 5: 419-426.

Hsu, T.-A., J. J. Eiden, P. Bourgarel, T. Meo and M. J. Betenbaugh (1994) Effects of co-expressing chaperone BiP on functional antibody production in the baculovirus system. Protein Express. Purif. 5: 595-603.

Hunter, F. R., N. E. Crook and P. F. Entwistle (1984) Viruses as pathogens for the control of insects. In Microbial Methods for Environmental Biotechnology (J. M. Grainer and J. M. Lynch eds.). Academic Press, New York, pp. 323-347.

Kunimi, Y., J. R. Fuxa and B. D. Hammock (1996) Comparison of wild type and genetically engineered nuclear polyhedrosis viruses of Autographa californica for mortality, virus replication and polyhedra production in Trichoplusia ni larvae. Entomol. Exp. Appl. 81: 251-257.

Lu, A., S. Seshagiri and L. K. Miller (1996) Signal sequence and promoter effects on the efficacy of toxin-expressing baculoviruses as biopesticides. Biol. Control 7: 320-332.

Maeda, S. (1989) Increased insecticidal effect by a recombinant baculovirus carrying a synthetic diuretic hormone gene. Biochem. Biophys. Res. Commun. 165: 1177-1183.

Maeda, S., S. L. Volrath, T. N. Hanzlik, S. A. Harper, K. Majima, D. W. Maddox, B. D. Hammock and E. Fowler (1991) Insecticidal effects of an insect-specific neurotoxin expressed by a recombinant baculovirus. Virology 184: $777-780$
McCutchen, B. F., P. V. Choudary, R. Crenshaw, D. Maddox, S. G. Kamita, N. Palekar, S. Volrath, E. Fowler, B. D. Hammock and S. Maeda (1991) Development of a recombinant baculovirus expressing an insect-selective neurotoxin: potential for pest control. BioTechnology 9: 848852.

Merryweather, A. T., U. Weyer, M. P. G. Harris, M. Hirst, T. Booth and R. D. Possee (1990) Construction of genetically engineered baculovirus insecticides containing the Bacillus thuringiensis supsp. kurstaki HD-73 delta endotoxin. J. General Virol. 71: 1535-1544.

Pinot, F., D. F. Grant, J. K. Beetham, A. G. Parker, B. Borhan, S. Landt, A. D. Jones and B. D. Hammock (1995) Molecular and biochemical evidence for the involvement of the Asp-333-His-523 pair in the catalytic mechanism of soluble epoxide hydrolase. J. Biol. Chem. 270: 7968-7974.

Prikhod'ko, G. G., M. Robson, J. W. Warmke, C. J. Cohen, M. M. Smith, P. Wang, V. Warren, G. Kaczorowski, L. T. Van der Ploeg and L. K. Miller (1996) Properties of three baculovirus-expressing genes that encode insect-selective toxins: $\mu$-Aga-IV, As II, and Sh I. Biol. Control 7: 236244.

Rubin, D. M., A. D. Mehta, J. Zhu, S. Shoham, X. Chen, Q. R. Wells and K. B. Palter (1993) Genomic structure and sequence analysis of Drosophila melanogaster HSC70 genes. Gene 128: 155-163.

Stewart, L. M., M. Hirst, F. M. Lopez, A. T. Merryweather, P. J. Cayley and R. D. Possee (1991) Construction of an improved baculovirus insecticide containing an insect-specific toxin gene. Nature 352: 85-88.

Tomalski, M. D. and L. K. Miller (1991) Insect paralysis by baculovirus-mediated expression of a mite neurotoxin gene. Nature 352: 82-85.

Ward, V. K., B. C. Bonning, T. Huang, T. Shiotsuki, V. N. Griffeth and B. D. Hammock (1992) Analysis of the catalytic mechanism of juvenile hormone esterase by site-directed mutagenesis. Int. J. Biochem. 24: 1933-1941. 